\title{
Effects of Additional Oxygen Supply in Single Cylinder Diesel Fuel Using Variable Compression Ratio Engine
}

\author{
JitinYadav $^{1}$, Dhananjay Gupta ${ }^{2}$, Manu Gupta ${ }^{3}$ \\ ${ }^{1}$ Ph.D. Scholar, Department of Research, Sunrise University, Alwar, Rajasthan, India, \\ Email-jtinrao@gmail.com, \\ ${ }^{2}$ Department of Mechanical Engineering, Arya College of Engineering and I.T., Jaipur, Rajasthan, India, \\ ${ }^{2}$ Department of Mechanical Engineering, Arya College of Engineering and I.T., Jaipur, Rajasthan, India,
}

\begin{abstract}
In the present study, a variable compression single cylinder diesel engine was used to study the effects of oxygen enrichment on the performance of engine at different compression ratios (C.R.) from 16.5 to 19.5 at different loads and compared to the amount of additional oxygen in four different rates from $1 \mathrm{~L} / \mathrm{min}$ to $4 \mathrm{~L} / \mathrm{min}$. Oxygen cylinders were connected to intake manifold with throttle valve to supply additional oxygen. Enrichment of oxygen favours combustion in many performance parameters so the tests were carried out for the brake power (B.P.), Mean effective pressure, $\left(P_{\text {met }}\right)$, specific fuel consumption (S.F.C.), Mechanical efficiency ( $\eta_{\text {mecheff }}$ ) and exhaust gas temperature (E.G.T.). The purpose of this study is to deal with the major technological characteristic of enriched oxygen used in variable compression ratio single cylinder diesel engine for best possible values of secure engine limits. The test results show that the combustion performances were enhanced as there was increase in B.P., $P_{\text {mef }}$ and decrease in S.F.C. and increase in rate of oxygen in intake air increases the charge burning rates and flame combustibility resulting higher exhaust gas temperature. Overall mechanical efficiency in lower compression ratio was high but for higher compression ratios there was a drop in mechanical efficiency.
\end{abstract}

Keywords - Oxygen Enrichment, Variable Compression Ratio, Brake Power, Specific Fuel Consumption, Exhaust Gas Temperature.

\section{INTRODUCTION}

In diesel engine combustion, ratio of fuel varies according to load requirements, so principle of using air in diesel engines says that excess air improves mixing rates but at the time of exhaust, it also carry heat at higher rates which affect the thermal efficiency of each cycle. In the mixture of fuel and air in small diesel engines mixing rates depend on many designs and operating variables and those variables will affect the performance of any engine. According to research under the subject of oxygen enrichment, it results that a certain level of oxygenation can improve the mixing rates to increase the performance and reduce the certain amount of emissions ${ }^{[1][5]}$.

The investigation and research in this field are very vast and conclusive in many respects. All results show a considerable increase in oxides of nitrogen and decrease in smoke, carbon monoxides and unburned hydrocarbons as the ratio of oxygen increases. Reduction in engine noise due to elevated oxygen level in induced air is also concluded by researchers ${ }^{[4]}$. Higher oxygen concentrations increase the mixtures' burning rate at the same compression ratio and low quality fuel can also be used in engines without much affecting the performance. The main drawback of oxygen enrichment is higher level of oxides of nitrogen in exhaust due to increased maximum pressure in combustion chamber. The efforts of many researchers conclude a range of percentage of maximum concentration of oxygen in intake is $30 \%$ by volume in which both particulate matters and oxides of nitrogen can be reduced for a fixed geometry engine ${ }^{[8]}$. Higher concentrations of oxygen cannot be controllable in combustion reaction. Oxygen enhancement can be done by two ways i.e. fuel oxygenation and intake air oxygenation ${ }^{[2]}$. In fuel oxygenation the diesel blends are used which carries oxygen in their molecular structure and there are many types of blends had been used ${ }^{[17]}$. In intake air oxygenation, pure oxygen is added in intake air by volume. Some researchers also made a membrane which is used in nitrogen separation so level of oxygen increased in induction phase ${ }^{[3]}$. The most convenient method for research is adding raw oxygen to intake for certain percentage by volume. Oxygenation methods also improves the emission and performance for biodiesels and diesel blends ${ }^{[6][10][19]}$.

For a fixed volume of combustion chamber and rated speed, a certain amount of oxygen can be added for optimum values of emission because the limitation of maximum pressure and temperature, that can be further controllable by the help of different compression ratios. Thus the purpose of the study to investigate the effect of oxygen enriched combustion at different compression ratio on a single cylinder four stroke naturally aspirated diesel engine with different level of oxygen concentration and compression ratios. 


\section{A. Engine Specifications}

\section{EXPERIMENTAL METHODS}

Single cylinder direct injection naturally aspirated water cooled four stroke compression ignition engine having the following specifications in Table I and fuel specifications in Table II was used for conducting experiments.

Table I Engine Specifications

\begin{tabular}{|l|l|}
\hline \multicolumn{2}{|c|}{ Engine Specifications } \\
\hline Bore $\times$ Stroke & $87.5 \times 110 \mathrm{~mm}$ \\
\hline Compression Ratio & 16 to $22: 1$ \\
\hline Rated Power & $5 \mathrm{~kW}$ \\
\hline Rated Speed & $1500 \mathrm{RPM}$ \\
\hline Cubic Capacity & 0.662 Litre \\
\hline Fuel Injection & Direct Injection \\
\hline Injection Timing & 21 degree BTDCA \\
\hline Injection Pressure & 230 Bar \\
\hline Type Kirloskar & TAF 1 \\
\hline Number of Cylinders & 1 \\
\hline
\end{tabular}

Table II Properties of Diesel Fuel Used in Test

\begin{tabular}{|c|c|}
\hline \multicolumn{2}{|c|}{ Fuel Properties of Diesel Used in Tests } \\
\hline Density at $15^{\circ} \mathrm{C}\left(\mathrm{kg} / \mathrm{m}^{3}\right)$ & 840 \\
\hline HHV $(\mathrm{MJ} / \mathrm{kg})$ & $44.65 \mathrm{MJ} / \mathrm{kg}$ \\
\hline LHV $(\mathrm{MJ} / \mathrm{kg})$ & $42.15 \mathrm{MJ} / \mathrm{kg}$ \\
\hline Viscosity $\left(\mathrm{mm}^{2} / \mathrm{s}\right)$ & 3.647 \\
\hline Compression Ratio & 17 \\
\hline Flash Point $\left({ }^{\circ} \mathrm{C}\right)$ & 64 \\
\hline Pour Point $\left({ }^{\circ} \mathrm{C}\right)$ & -6 \\
\hline C $(\mathrm{wt} \%)$ & 85.0 \\
\hline H $(\mathrm{wt} \%)$ & 13.0 \\
\hline Sulphur Content $(\mathrm{wt} \%)$ & 0.85 \\
\hline Water Content $(\mathrm{mg} / \mathrm{kg})$ & 97 \\
\hline
\end{tabular}

\section{B. Experimental Setup}

A vertical variable compression ratio (VCR) engine were used which is manually adjusted by the help of one nut which is fixed at frame with the help of stud. One dial indicator was used to measure the tilt of the engine. After that it was fixed by the two lock nuts in a position for the readings for different oxygen ratios. The range of the VCR is $16.5,17.5,18.5$ and 19.5. This test rig is brought up by Company 'K.C. Engineering, Ambala' which assembles all the sensors, accessories, dynamometer and calorimeter with taking care of calibration and errors. Intake oxygen was added by using oxygen cylinder, mounted with a flow control valve, just at the inlet of air surge tank by using flow regulating valve in order to give the adequate time for mixing. To protect the engine, low levels of intake oxygen was used in intake air. Only four levels were studied which are $1 \mathrm{~L} / \mathrm{min}$, $2 \mathrm{~L} / \mathrm{min}, 3 \mathrm{~L} / \mathrm{min} \& 4 \mathrm{~L} / \mathrm{min}$. The naturally available oxygen is $21 \%$ by volume so the valve was completely off at first ratio. The mass balance was used to measure the fuel flow rate with an accuracy of $0.01 \mathrm{~g}$. The test rig is coupled with (Model) eddy current dynamometer. A kistler's piezo-electric transducer measures the combustion chamber pressure with an increment of 1 degree crank angle using data acquisition system (Company and model). Thermocouples were used to measure the temperature of inlet air, engine coolant jacket inlet, engine coolant jacket outlet, calorimeter outlet, exhaust temperature and exhaust temperature at outlet after calorie meter. A two way float type flow regulator was used to regulate the water in the engine cooling jackets and calorimeter. A crank angle sensor were used to measure the crank position is coupled with the help of pulley to the crankshaft. A four gases exhaust gas analyser is used to measure the $\mathrm{CO}, \mathrm{CO}_{2}, \mathrm{HC}$ and $\mathrm{NO}_{\mathrm{x}}$. All the specifications are given in detail in Table III. 


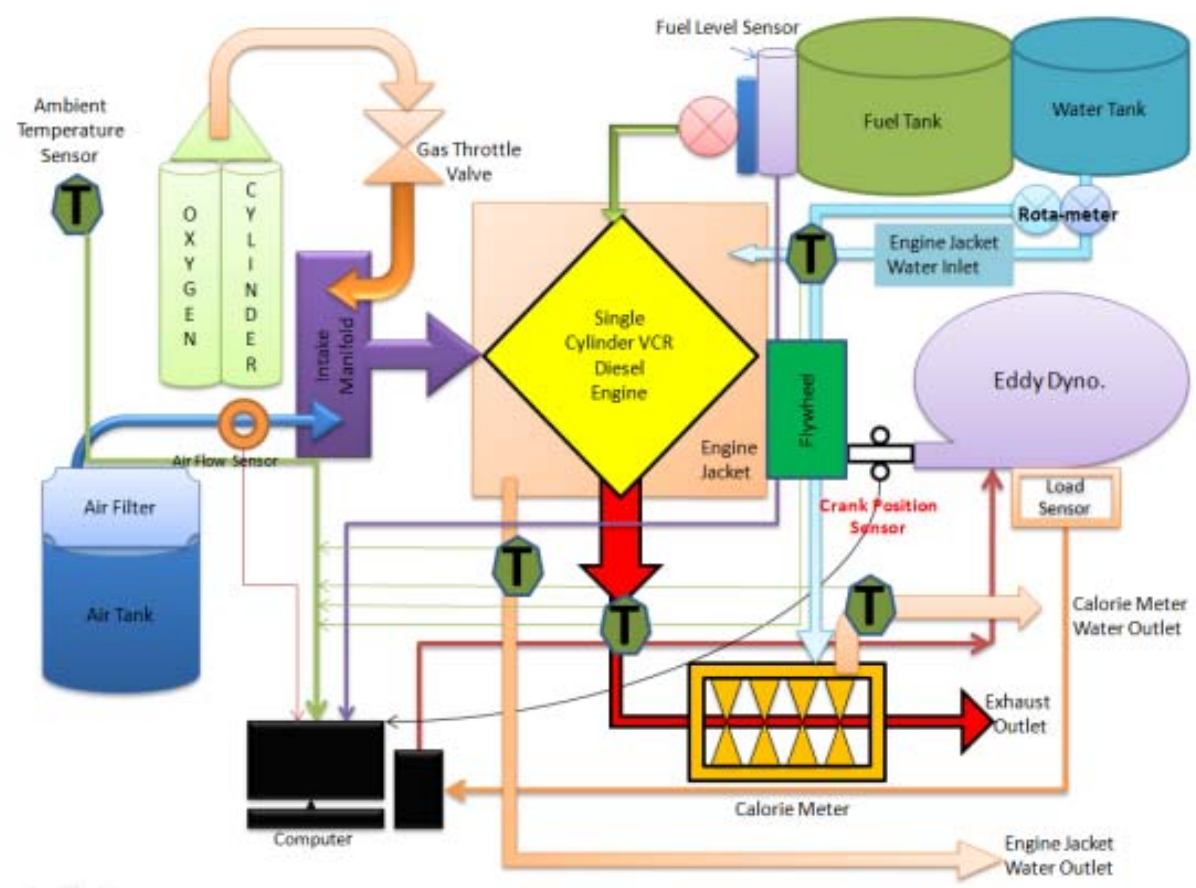

Fig. 1. Experimental Schematic of Test Rig

Table III Experimental Setup

\begin{tabular}{|l|l|}
\hline \multicolumn{2}{|c|}{ Experimental Setup Specifications } \\
\hline Calorimeter & Pipe in Pipe type \\
\hline Piezo Sensor & Range 5000 PSI, with low noise cable \\
\hline Crank Angle Sensor & Resolution 1 Deg, Speed 5500 RPM with TDC pulse \\
\hline Temperature Sensor & RTD Type PT-100 and Thermocouple, K Type \\
\hline $\begin{array}{l}\text { Temperature } \\
\text { Transmitter }\end{array}$ & $\begin{array}{l}\text { 2 wire, I/P RTD PT-100, 0-100 Deg C, O/P 4-20mA, Type 2 wire, } \\
\text { Input TC, 0-1200 Deg C, Output 4-20 mA }\end{array}$ \\
\hline Type of Loading & Eddy Current Dynamometer \\
\hline Load Indicator & Digital, Range: 0-50 kg, Supply : 230VAC \\
\hline Load Sensor & Load Cell, type strain gauge, Range : 0-50 Kg \\
\hline Fuel Flow Transmitter & DP transmitter, Range : 0-500 mm WC \\
\hline Air Flow Transmitter & Pressure Transmitter, Range (-) 250 mm WC \\
\hline Rotameter & Engine cooling 40-400 LPH, Calorimeter 25-250 LPH \\
\hline Pump & Type Mono Block \\
\hline Water Supply & $\begin{array}{l}\text { Continuous, clean and soft water supply @5000 LPH, at 10m. Head, } \\
\text { Provide tap with 1" BSP size connection }\end{array}$ \\
\hline Computer System & i-3 processor with DVD Drive, Windows 7 and MS Office pre-loaded. \\
\hline Electric Supply & 230+/- 10 V AC, 50 Hz, 1 Phase. \\
\hline Manatec Eco Gas 100 & $\begin{array}{l}\text { Gas Analyser with NDIR technology, Measurement of CO (Range: 0- } \\
15 \% \text { ), CO2 (Range: 0-19.9\%), HC (Range: 0-20000ppm) and NOx } \\
\text { (Range: 0-5000ppm), }\end{array}$ \\
\hline
\end{tabular}




\section{Experimental Procedure}

The tests were operated in a cabin at the ambient temperature of $27^{0} \mathrm{C}$. Tests were carried out different compression ratio (CR), starting with $16.5 \mathrm{CR}$ to an incremental $\mathrm{CR}$ of 1 after completing the cycle of one loading at all four fraction of oxygen concentrations. Different loading of starting from Zero load to the rated capacity of the engine to the successive loading of increment of $20 \%$ is used after every change in CR at a constant speed of 1500 RPM. Steadiness and reiterating of the conditions of operation were ensured by primarily run the test rig for 15 minutes at 50 percent load for constant $1500 \mathrm{rpm}$ until the exhaust gas temperature reached 250 degree centigrade. The flow of water in engine jacket and calorimeter was fixed a 60 Litre per minute by the regulating rota-meter. It was ensured that the temperature of intake water was constant throughout in collecting data. Once these conditions were attained, the engine test rig was brought to the essential test conditions and permitted it to run for 5 minutes to ensure to stabilize reading before collecting the records. The fuel injection pressure and its injection timing was constant while experiment as per the company's standards. The diameter of exhaust pipe was increased by $15 \%$ to avoid the possibilities of backpressure.

\section{RESULTS AND DISCUSSION}

The prime objective of the research is to study the performance parameters affected by the varying oxygen level at different compression ratios. Basic performance parameters like B.P., S.F.C., $\eta_{\text {mecheff, }} P_{\text {mef }}$, and E.G.T. were used in data collection with stabilised engine conditions.

\section{A. Brake Power}

This power is usable power delivered by the engine to the load. Increase in oxygen concentration increase the mixture ratio of specific heat, this increases the conversion rate of the mixture thermal energy to work energy. The $\mathrm{NO}_{\mathrm{x}}$ level increases as the oxygen percentage increases ${ }^{[6]}{ }^{[8][9]}$. The oxygen concentration increases the brake power significantly increases ${ }^{[13]}[14][15]$. Fig. 2. indicates that BP increases when the compression ratio increases with increment in oxygen concentrations. Up to $36 \%$ increment in power was observed at full load when oxygen concentration is increased to $4 \mathrm{~L} / \mathrm{min}$ when compared to $1 \mathrm{~L} / \mathrm{min}$. While increasing compression ratios, maximum brake power was observed at $3 \mathrm{~L} / \mathrm{min}$ of oxygen enrichment.

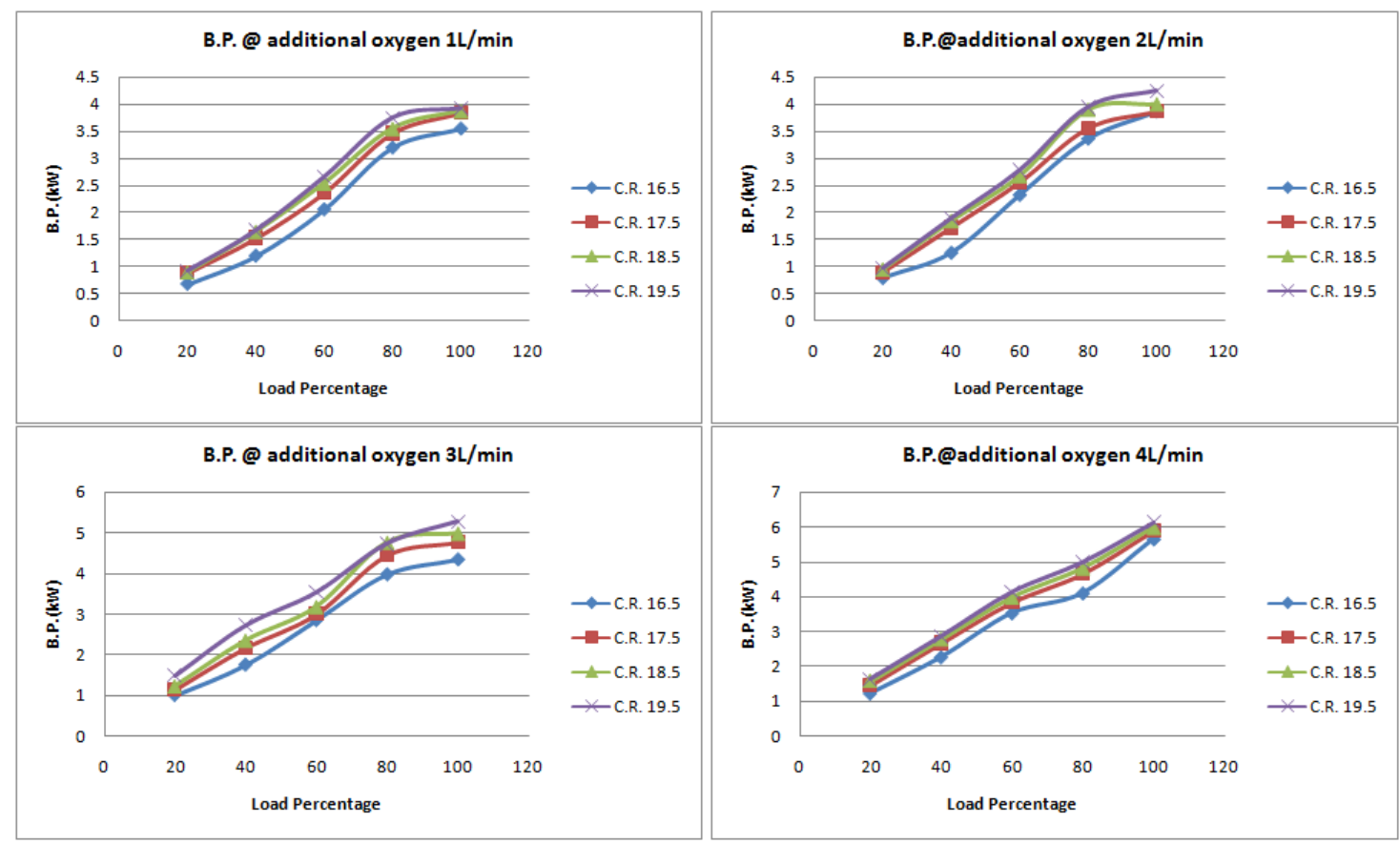

Fig. 2. Brake power with different oxygen concentrations at different compression ratios

\section{B. Mechanical Efficiency}

Mechanical efficiency is the ratio of the brake power delivered by the engine to the indicated power. So when the brake power increases the mechanical efficiency increases ${ }^{[8]}{ }^{[16]}$. A set of data is collected for mechanical efficiency at different loads, oxygen concentrations and compression ratios. It can be seen in Fig. 3. that average of $6 \%$ increase in mechanical efficiency is obtained for an enrichment of $2 \mathrm{~L} / \mathrm{min}$ when compared with $1 \mathrm{~L} / \mathrm{min}$ at compression ratio at 16.5 and 17.5 and the maximum of $14 \%$ can be obtained for enrichment of $4 \mathrm{~L} / \mathrm{min}$ oxygen when compared to $1 \mathrm{~L} / \mathrm{min}$ of oxygen enrichment. At compression ratio 16.5 and 17.5 mechanical efficiency goes up at all the oxygen enrichment levels from $1 \mathrm{~L} / \mathrm{min}$ to $4 \mathrm{~L} / \mathrm{min}$ but its average of $7 \%$ decreases as compression ratio increases to 18.5 to 19.5 at the $3 / 4^{\text {th }}$ load and full load conditions. 


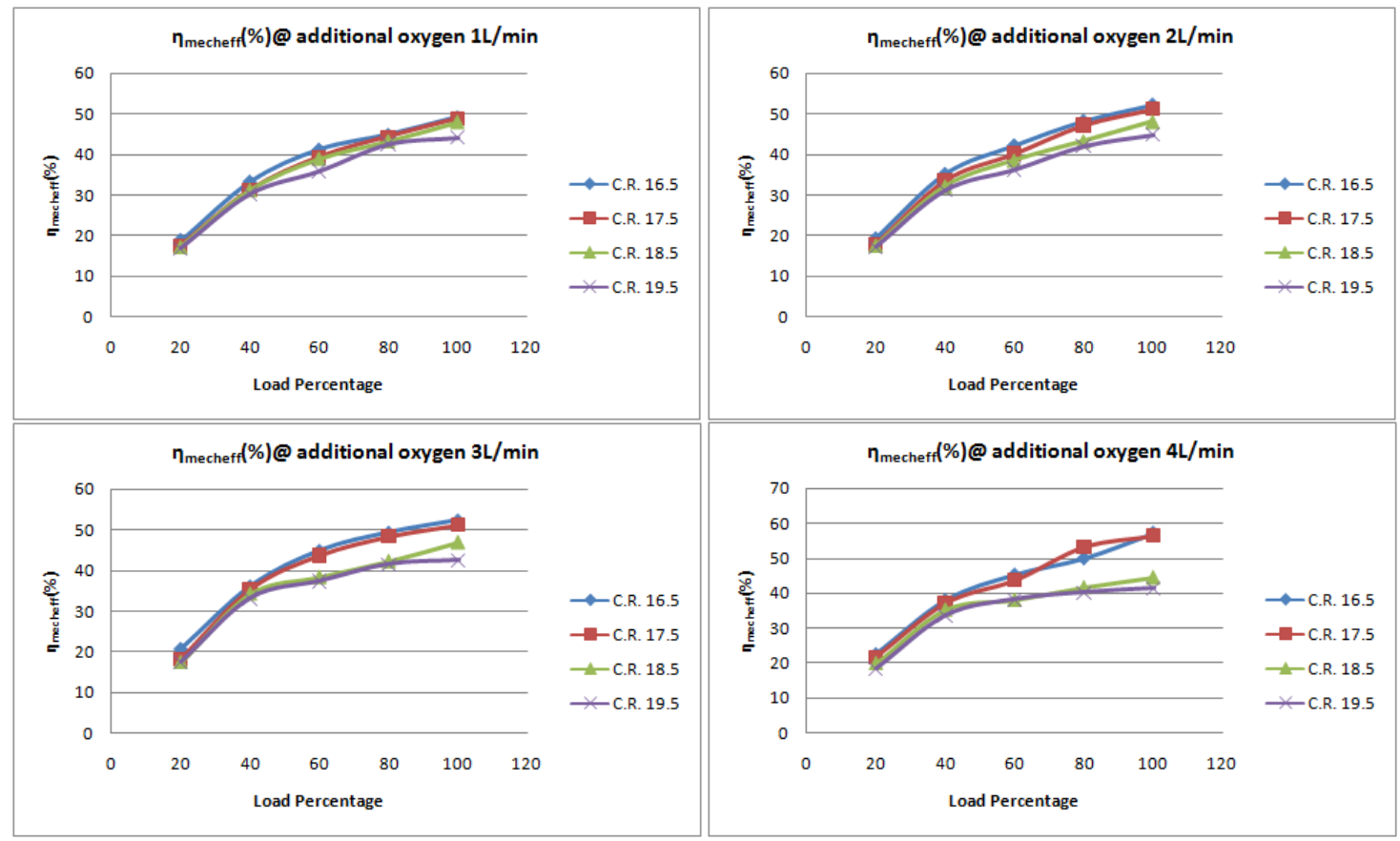

Fig. 3. Mechanical Efficiency with different oxygen concentrations at different compression ratios

\section{Specific Fuel Consumption}

The fuel flow rate per unit power output is called S.F.C. It measures how efficiently an engine is using the fuel supplied to produce the work ${ }^{[4]}$. With reference to Fig. 4. as the level of oxygen increases from 1L to $4 \mathrm{~L} / \mathrm{min}$ the specific fuel consumption decreases average by $37 \%$ at full load condition but subsequently as the compression ratio increases from 16.5 to 19.5 , average $41.25 \%$ increment was observed during full load conditions. This means as the compression ratio goes up the S.F.C. goes up but as the pure oxygen increases in intake the level of S.F.C. decreased. So the higher compression ratios can help in decrease in S.F.C. by utilizing the fuel properly for better engine outputs even at higher oxygen levels.

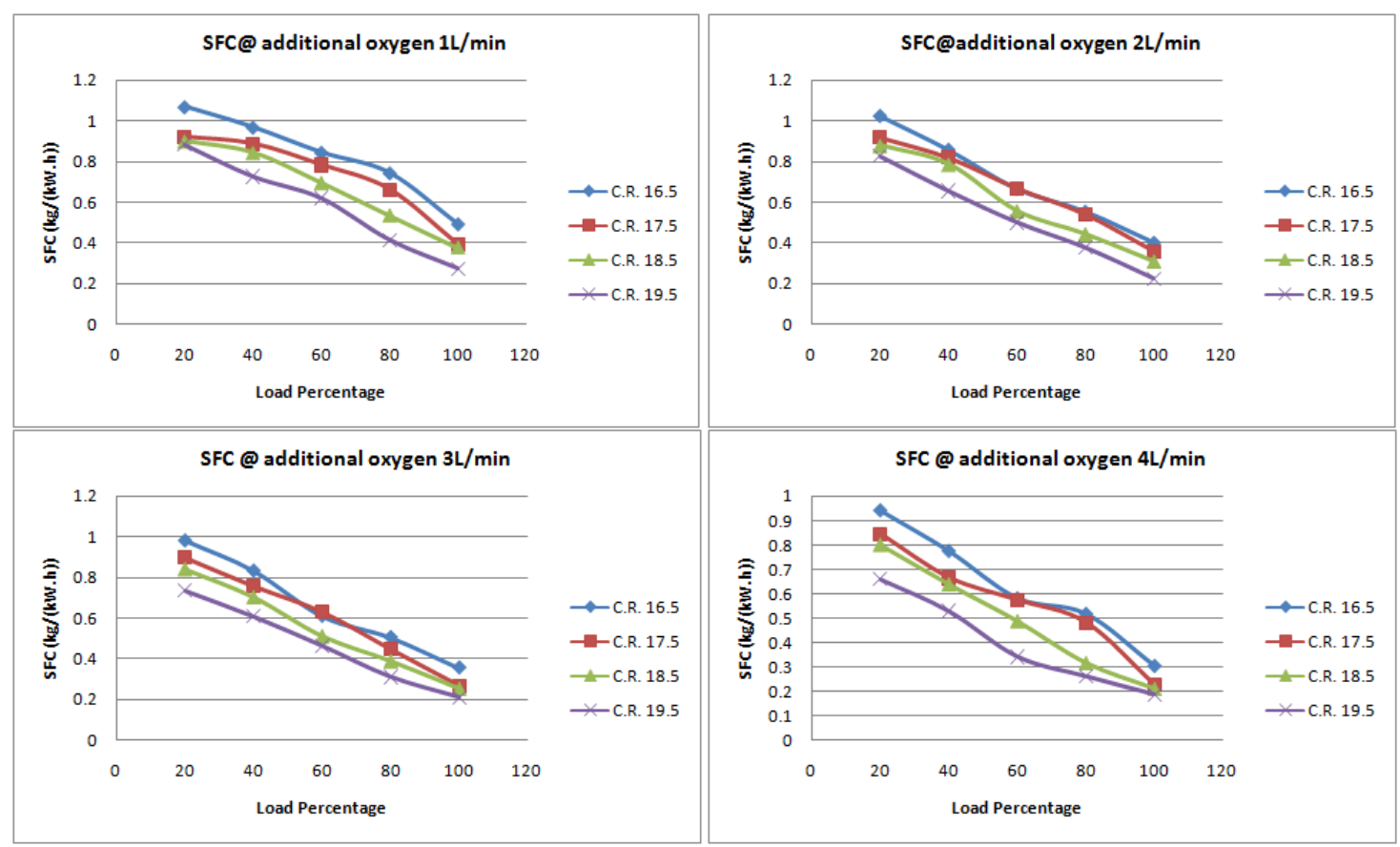

Fig. 4. Specific fuel consumption with different oxygen concentrations at different compression ratios 


\section{Mean Effective Pressure}

This is useful engine performance parameter measure which is obtained by dividing the work per cycle by the cylinder volume displaced per cycle. The higher oxygen fraction in mixture can decrease the tendency of low peak pressure at constant load ${ }^{[12]}$. From the sets of data collected, it was observed according to the Fig. 5. that cylinder peak pressure was increased in the range of 14 to $23 \%$ as the oxygen level increased at full load condition from $1 \mathrm{~L}$ to $4 \mathrm{~L} / \mathrm{min}$ and as the compression ratio is increased resulting increased in the mean effective pressure by 10 to $18 \%$ at full load with different oxygen concentration levels.

\section{E. Exhaust Gas Temperature}

Higher combustion efficiency can be observed with the higher exhaust gas temperatures. So the higher output of exhaust gas is the simplest form to study the combustion efficiency ${ }^{[14]}$. Higher oxygen levels in mixture can increase the combustion rate and high compression ratios also increase the temperature by increasing the pressure resulting higher temperatures of exhaust gas due to more complete combustion ${ }^{[15]}$. The conclusion was drawn from the sets of data as shown in Fig. 6. that the temperature of exhaust is increased average by $35^{\circ} \mathrm{C}$ when oxygen level was increased from $1 \mathrm{~L}$ to $4 \mathrm{~L} / \mathrm{min}$ at full load conditions. The second observation was that when the compression ratio is increased from 16.5 to 19.5 , the peak pressure is further increased and resulting in average increment of exhaust gas temperature $51{ }^{\circ} \mathrm{C}$.

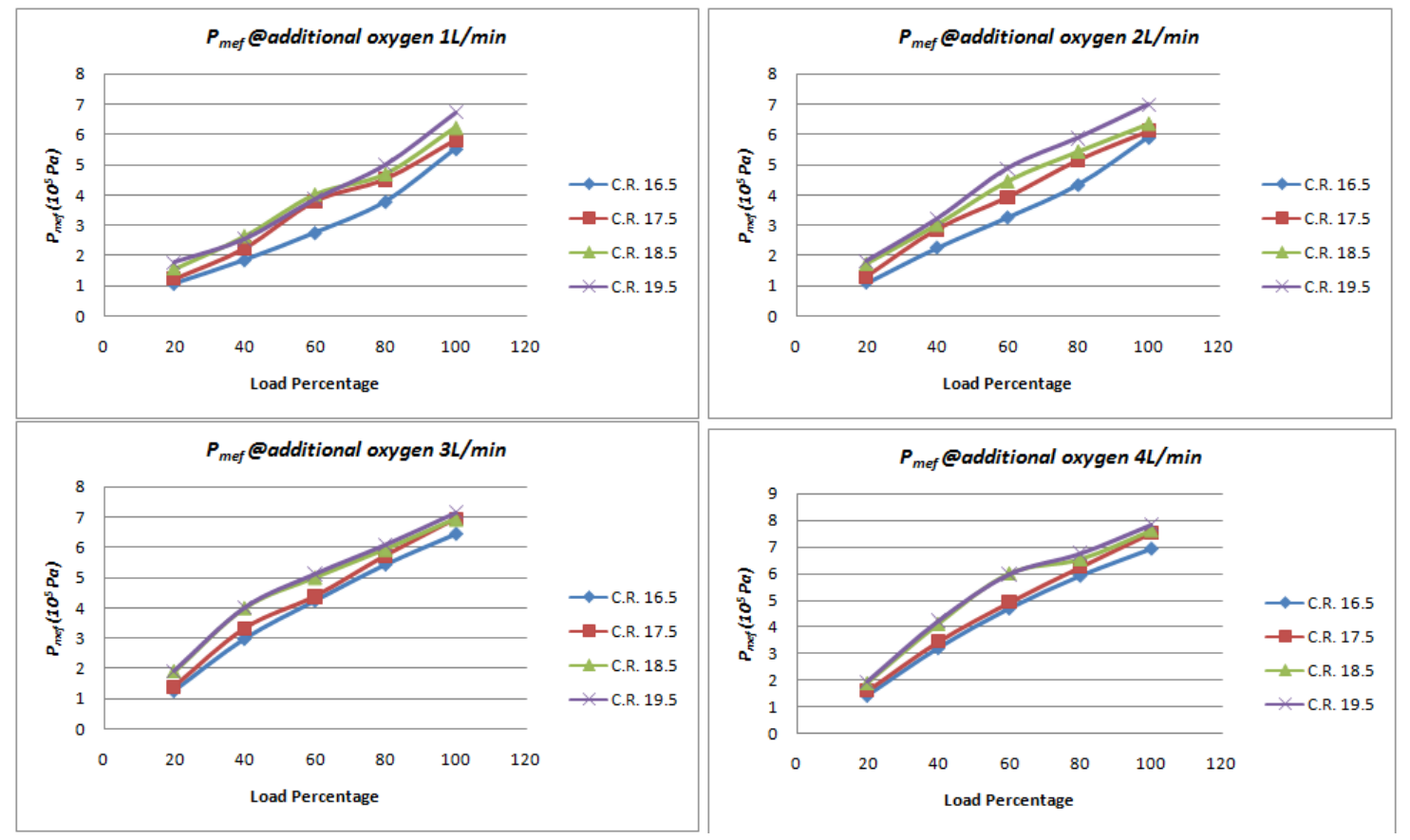

Fig. 5. Mean effective pressure with different oxygen concentrations at different compression ratios 


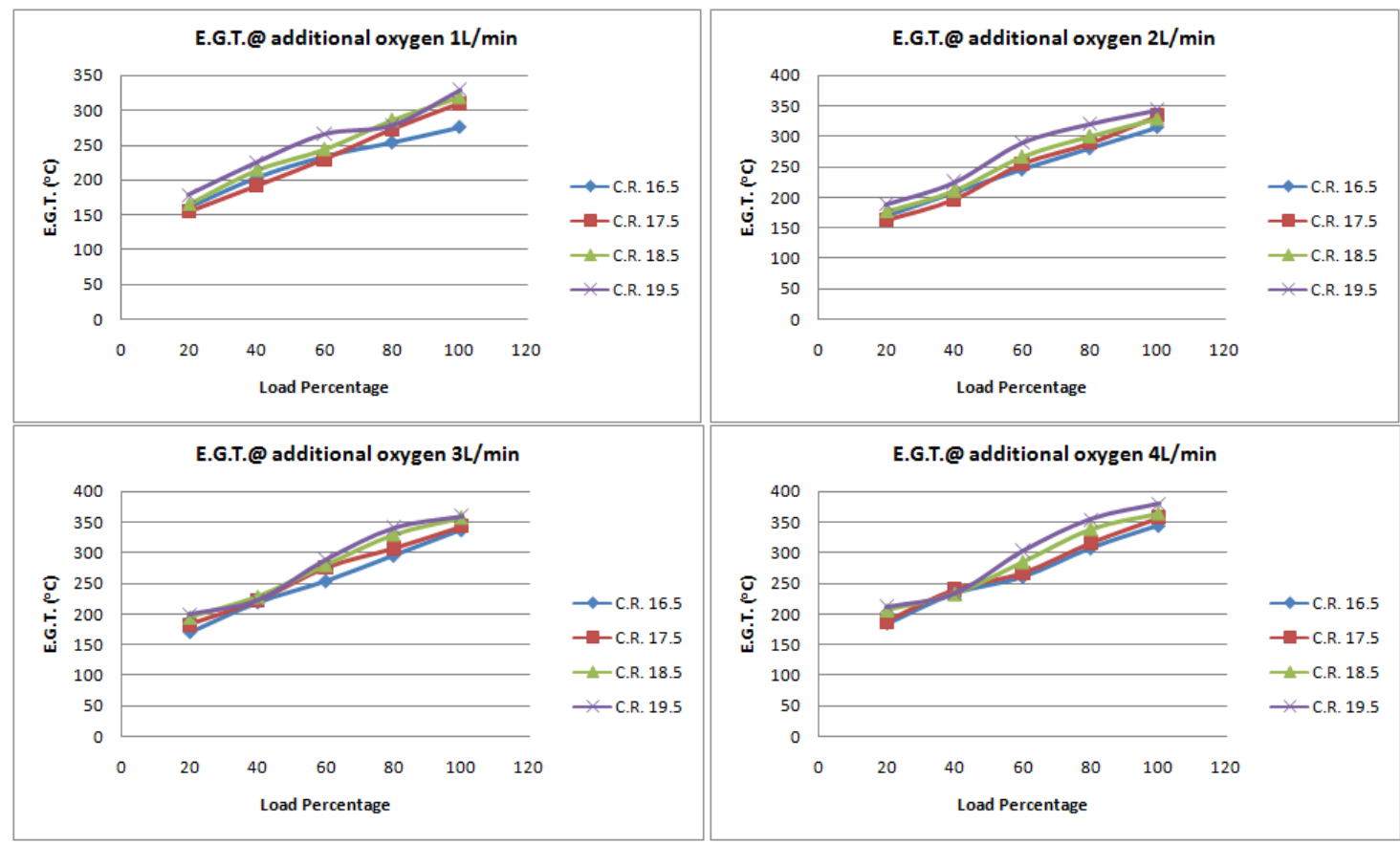

Fig. 6. Exhaust gas temperature with different oxygen concentrations at different compression ratios

\section{CONCLUSION}

A variable compression ratio single cylinder diesel engine was used to study about the change in performance parameters by using enriched oxygen level at different compression ratios. The following point can be concluded from the research:

1) When compared to $1 \mathrm{~L} / \mathrm{min}$ to $4 \mathrm{~L} / \mathrm{min}$ of oxygen enrichment, the increment in B.P. was calculated $36 \%$ at full load condition and maximum B.P. output was recorded at $3 \mathrm{~L} / \mathrm{min}$.

2) Increase in mechanical efficiency was recorded $14 \%$ for compression ratio 16.5 and 17.5 at all load conditions from $1 \mathrm{~L}$ to $4 \mathrm{~L} / \mathrm{min}$ but decrease of $7 \%$ in compression ratio 18.5 and 19.5 for full load conditions at $3 \mathrm{~L}$ and $4 \mathrm{~L} / \mathrm{min}$.

3) A decrease in specific fuel consumption was average $37 \%$ but due to increase in compression ratio it was increased slightly up when compression ratio was increased.

4) Due to increase in oxygen level, the mean effective pressure can be increase up to 14 to $23 \%$. The compression ratio can further increase the mean effective pressure by 10 to $18 \%$.

5) Combustion efficiency was recorded effective at higher level of intake oxygen due to exhaust gas temperature increased by $35^{\circ} \mathrm{C}$. Due to increase in compression up to 19.5 , the temperature difference can go up to $53^{\circ} \mathrm{C}$.

6) Since the required modifications in the existing intake system are not complex, an additional mixing chamber is required for mixing the atmospheric air with the oxygen. As the compression ratio increases, it helps in additional boost with the oxygen enrichment for complete combustion and better efficiency.

\section{ACKNOWLEDGMENT}

The authors are thankful to management of Arya College of Engineering and I.T., Jaipur to give permission for conducting tests in their labs by using their test rigs and emission equipments.

\section{REFERENCES}

[1] P. Baskar and A. Senthilkumar, "Effects of oxygen enriched combustion on pollution and performance characteristics of a diesel engine," Eng. Sci. Technol. an Int. J., vol. 19, no. 1, pp. 438-443, 2016.

[2] G. Bisio, A. Bosio, and G. Rubatto, "Thermodynamics applied to oxygen enrichment of combustion air," Energy Convers. Manag., vol. 43, no. 18, pp. 2589-2600, 2002.

[3] H. Byun, B. Hong, and B. Lee, "The effect of oxygen enriched air obtained by gas separation membranes from the emission gas of diesel engines," Desalination, vol. 193, no. 1-3, pp. 73-81, 2006.

[4] J.B. Heywood, Internal combustion Engine Fundamental, Mc-Graw Hill, 1988.

[5] Charles E. Baukal, Oxygen Enhanced Combustion. CRC Press LLC, 1998.

[6] P. Dinesha, V. Nayak, and P. Mohanan, "Effect of oxygen enrichment on the performance, combustion, and emission of single cylinder stationary CI engine fueled with cardanol diesel blends," J. Mech. Sci. Technol., vol. 28, no. 7, pp. 2919-2924, 2014.

[7] D. Lahiri, P. S. Mehta, R. B. Poola, and R. R. Sekar, "Utilization of Oxygen-Enriched Air in Diesel Engines: Fundamental Considerations," Intern. Combust. engine 1997 fall Conf., 1997.

[8] H. Li, P. Biller, S. A. Hadavi, G. E. Andrews, G. Przybyla, and A. Lea-Langton, "Assessing combustion and emission performance of direct use of SVO in a diesel engine by oxygen enrichment of intake air method," Biomass and Bioenergy, vol. 51, pp. 43-52, 2013. 
[9] Y. Liang, G. Shu, H. Wei, and W. Zhang, "Effect of oxygen enriched combustion and water-diesel emulsion on the performance and emissions of turbocharged diesel engine," Energy Convers. Manag., vol. 73, pp. 69-77, 2013.

[10] M. S. Moghaddam, A. Zarringhalam, N. G. Zanjani, and E. Salimipor, "Improvement fuel properties and emission reduction by use of Diglyme-Diesel fuel blend on a heavy-duty diesel engine," 2nd Int. Conference Environ. Eng. Appl., vol. 17, pp. 210-214, 2011.

[11] S. H. Park, H. J. Kim, and C. S. Lee, "Effects of dimethyl-ether (DME) spray behaviour in the cylinder on the combustion and exhaust emissions characteristics of a high speed diesel engine," Fuel Process. Technol., vol. 91, no. 5, pp. 504-513, 2010.

[12] P. L. Perez and A. L. Boehman, "Performance of a single-cylinder diesel engine using oxygen-enriched intake air at simulated highaltitude conditions," Aerosp. Sci. Technol., vol. 14, no. 2, pp. 83-94, 2010.

[13] R. B. Poola, R. Sekar, D. N. Assanis, and G. R. Cataldi, "Study of Using Oxygen-Enriched Combustion Air for Locomotive Diesel Engines," no. 1, 1996.

[14] K. Rajkumar and P. Govindarajan, "Impact of oxygen enriched combustion on the performance of a single cylinder diesel engine," Front. Energy, vol. 5, no. 4, pp. 398-403, 2011.

[15] K. Rajkumar, P. Govindarajan, C., "Experimental Investigation of Oxygen Enriched air intake on Combustion Parameters of a Single Cylinder Diesel Engine," Int. J. Eng. Sci. Technol., vol. 2, no. 8, pp. 3621-3627, 2010.

[16] G. Reddy, N. Pratap Singh, K. R. V Sai Krishna, A. Priyedarshi, and S. Singh, "Effect Of Compression Ratio On The Performance of Diesel Engine at Different Loads," J. Eng. Res. Appl., vol. 5, no. 102, pp. 2248-962262, 2015.

[17] G. R. Rigby and H. C. Watson, "Application of membrane gas separation to oxygen enrichment of diesel engines," J. Memb. Sci., vol. 87, no. $1-2$, pp. $159-169,1994$.

[18] J. Song, V. Zello, A. L. Boehman, and F. J. Waller, "Comparison of the impact of intake oxygen enrichment and fuel oxygenation on diesel combustion and emissions," Energy and Fuels, vol. 18, no. 5, pp. 1282-1290, 2004.

[19] G. Yanfeng, L. Shenghua, G. Hejun, H. Tiegang, and Z. Longbao, "A new diesel oxygenate additive and its effects on engine combustion and emissions," Appl. Therm. Eng., vol. 27, no. 1, pp. 202-207, 2007.

\section{AUTHOR PROFILE}

Jitin Yadav - He is graduated from M.D.U. Rohtak with a B.E. (Hons) in Automobile Engineering and then he did M.Tech in Thermal Power Engineering. Currently, he is doing his Ph.D. under the guidance of Dr. Prof. Dhananjay Gupta and Co- guide Prof. Manu Gupta. He has 4 years of teaching and research experience in department of Automobile and Mechanical engineering mainly in I.C. Engines and automobile engineering.

Dr. Prof. Dhananjay Gupta - He has 47 years of experience in teaching \& administration at various levels in Rajasthan Technical University, Kota. Prof. D. Gupta was Head of Mechanical Engineering Department, Engineering College, Kota. He had also been a member of Board of Management and Faculty of Engineering, Rajasthan Technical University, Kota. He is currently working as a Chairman, Governing Body of Arya College of Engineering and I.T., Jaipur. His expertise areas are I. C. Engines, Heat Transfer and Thermal Engineering.

Dr. Prof. Manu Gupta - He is working as Principal of Arya College of Engineering and I.T., Jaipur with 21 years of rich experience. He is expert of various subjects of mechanical engineering especially I.C. Engine and FEM and he is consistently working on many projects. 